\title{
Adverse Events Following International Normalized Ratio Reversal in Intracerebral Hemorrhage
}

\author{
Mona Laible ${ }^{a} \quad$ Ekkehart Jenetzkyd, h, i Christopher Beynon ${ }^{b}$ \\ Oliver Josef Müller ${ }^{b, c, e}$ Peter Sander ${ }^{a, j} \quad$ Svenja Schüler ${ }^{f} \quad$ Jan Purrucker ${ }^{a}$ \\ Markus Möhlenbruch ${ }^{g}$ Thorsten Steiner $^{\mathrm{a}, \mathrm{k}}$ Roland Veltkamp ${ }^{\mathrm{a}}$ I \\ Peter Arthur Ringleb ${ }^{a}$ Timolaos Rizos $^{a}$
}

Departments of a Neurology, ${ }^{b}$ Neurosurgery, and ${ }^{\mathrm{c} I n t e r n a l}$ Medicine III, Heidelberg University Hospital, ${ }^{\mathrm{d}}$ Division of Clinical Epidemiology and Aging Research, German Cancer Research Center, e DZHK (German Center for Cardiovascular Research), Partner Site Heidelberg/Mannheim, ${ }^{f}$ Institute of Medical Biometry and Informatics and gDepartment of Neuroradiology, Heidelberg University Hospital, Heidelberg, ${ }^{\mathrm{h}}$ Department for Child and Adolescent Psychiatry, Johannes Gutenberg-University, Mainz, 'Child Center Maulbronn gGmbH, Hospital for Paediatric Neurology and Social Paediatrics, Maulbronn, jDepartment of Cerebrovascular Diseases, Hetzelstift, Neustadt an der Weinstrasse, and kDepartment of Neurology, Klinikum Frankfurt Höchst, Frankfurt am Main, Germany; 'Department of Stroke Medicine, Imperial College London, London, UK

\section{Key Words}

Prothrombin complex concentrate · Vitamin K antagonists · Intracerebral hemorrhage · Reversal treatment .

Thromboembolic event · Allergic reaction

\begin{abstract}
Background: Prothrombin complex concentrates (PCCs) are frequently used to reverse the effect of vitamin Kantagonists (VKAs) in patients with non-traumatic intracerebral hemorrhage (ICH). However, information on the rate of thromboembolic events (TEs) and allergic events after PCC therapy in VKA-ICH patients is limited. Methods: Consecutive VKA-ICH patients treated with PCC at our institution between December 2004 and June 2014 were included into this retrospective observational study. We recorded international normalized ratio (INR) values before and after PCC treatment, baseline clinical characteristics including the premor-
\end{abstract}

bid modified Rankin Scale (pmRS) score, TE and allergic event that occurred during the hospital stay. All events were classified by 3 reviewers as being 'related', 'probably related', 'possibly related', 'unlikely related' or 'not related' to treatment with PCC. To identify factors associated with TEs, logrank analyses were applied. Results: Two hundred and five patients were included. Median INR was 2.8 (interquartile range (IQR) 2.2-3.8) before and 1.3 (IQR 1.2-1.4) after PCC treatment and a median of 1,500 IU PCC (IQR 1,000-2,500) was administered. Nineteen TEs were observed (9.3\%); none were classified 'related' but 9 were classified as 'possibly' or 'probably related' to PCC infusion (4.4\%). One allergic reaction $(0.5 \%)$, 'unlikely related' to PCC, was observed. In the whole cohort, PCC doses $>2,000-3,000 \mathrm{IU}, \mathrm{ICH}$ volumes $>40$ $\mathrm{ml}$, National Institute of Health Stroke Scale values $>10$ and a pmRS $>2$ were associated with the development of TEs ( $p=$ $0.031, p=0.034, p=0.050$ and $p=0.036$, respectively). Conclusions: Overall, INR reversal with PCC appears safe. Though

\section{KARGER}

E-Mail karger@karger.com

www.karger.com/ced
(C) 2016 S. Karger AG, Basel

$1015-9770 / 16 / 0426-0446 \$ 39.50 / 0$
Timolaos Rizos, MD

Department of Neurology

University Heidelberg

INF 400, DE-69120 Heidelberg (Germany)

E-Mail timolaos.rizos@med.uni-heidelberg.de 
no clear relationship between higher PCC dosing and TEs was observed, PCC doses between $>2,000$ and 3,000 IU and higher morbidity at ICH onset were associated with TEs. Hence, individual titration of PCC to avoid exposure to unnecessarily high doses using point-of-care devices should be prospectively explored.

(c) 2016 S. Karger AG, Base

\section{Introduction}

Intracerebral hemorrhages (ICHs) represent the most feared complication of treatment with oral anticoagulants [1, 2]. About $10-18 \%$ of all ICH cases are associated with vitamin $\mathrm{K}$ antagonists (VKAs) [3, 4], and with up to $54 \%$ of hematomas enlarging within the first hours after diagnosis, secondary hematoma growth in VKA-ICH is much more prevalent than in primary ICH $(16 \%)[5,6]$. Moreover, hematoma growth in VKA-ICH is often prolonged in time [7] and mortality rates considerably exceed the rates of primary ICH (34 vs. up to $67 \%$ ) [1, 2, 5-9].

To prevent hematoma enlargement and to reduce the associated risk of an unfavorable outcome including death $[10,11]$, guidelines recommend reversing the anticoagulatory effect of VKA in ICH patients as fast as possible $[3,10,12-14]$ and current guidelines for VKA reversal in ICH recommend prothrombin complex concentrates (PCCs) combined with vitamin $\mathrm{K}$ over fresh frozen plasma (FFP) [15]. PCC normalizes the international normalized ratio (INR) more rapidly compared to FFP [14, 16-18], a finding that has recently been confirmed impressively in patients with VKA-ICH as well [19]. Moreover, PCC does not require any serologic testing before administration and necessary infusion volumes are smaller compared to FFP [11, 20, 21]. Importantly, fast INR normalization appears to be associated with smaller hematoma expansion in VKA-ICH [19, 22].

According to a large meta-analysis, the risk of thromboembolic events (TEs) after PCC infusion is low $(\sim 1.8 \%)$, but indications for PCC treatment and sample sizes varied considerably between included studies [23].

Data on TEs related to reversal treatment with PCC in patients with VKA-ICH are surprisingly rare. A recent study evaluating the prevalence of adverse events in a homogenous population with VKA-ICH reported 2 TEs in 27 patients $(7.4 \%)$ within the first 3 days after therapy with PCC and another 5 TEs (18.5\%) within 3 months [19] after PCC treatment.

Prothrombin Complex Concentrate in $\mathrm{ICH}$
Here, we aimed to determine the rate of TE and allergic event after treatment with PCC in a large consecutive cohort of patients with VKA-ICH.

\section{Methods}

Consecutive patients who were treated with PCC between December 2004 and June 2014 at the Departments of Neurology and Neurosurgery, Heidelberg University Hospital, Germany, were included into a prospective database. All patients with non-traumatic VKA-ICH entered the present observational analysis. Patients with ICH due to cerebral venous thrombosis, trauma, tumors, subarachnoid hemorrhages, secondary ICH after thrombolysis or hemorrhagic transformation, non VKA-related coagulopathies and patients that were (co-)treated with recombinant factor VIIa or FFP were excluded. All neurosurgical interventions (e.g., hematoma evacuation, ventricular or hematoma drainage) were recorded. Analyzed data were obtained retrospectively from the patients' charts.

Standard procedures for all patients at admission encompassed a clinical examination, documentation of basic demographic variables and cardiovascular risk factors and brain imaging (CT or MRI). Stroke severity was assessed using the National Institute of Health Stroke Scale (NIHSS). Moreover, standardized laboratory testing, including a full blood count, glucose, electrolytes, urea, creatinine, prothrombin time and calculation of the INR was performed at admission.

In accordance with current guidelines $[10,14]$ and local standardized procedures, VKA reversal with PCC was started as fast as possible after diagnosis of ICH in patients with an INR $\geq 1.5$ until an INR $<1.5$ was achieved and coagulation tests were repeated after the end of PCC infusion in all patients. The time between symptom onset and first CT or MRI, leading to the diagnosis of ICH, and the time between diagnosis of ICH and successful INR reversal (INR $<1.5)$ were recorded.

The following 4-factor PCC products (i.e., PCCs containing factors II, VII, IX and factor VII [24]) were used to reverse anticoagulation: Beriplex $\mathrm{P} / \mathrm{N} 500^{\circledR}$ (CSL Behring GmbH, Marburg, Germany), Octaplex ${ }^{\circledR}$ (Octapharma, Langenfeld, Germany) and PPSB-Human SD/Nano $600^{\circledR}$ (Octapharma, Langenfeld, Germany; online suppl. table 1; for all online suppl. material, see www.karger.com/doi/10.1159/000448815). Dosing of PCC was based on INR values at admission and during follow-up measurements. Dosing of PCC was performed upon the decision of the treating neurologist and based on the following local recommendations: 1,000 IU PCC when the initial INR is $>1.8$; in case of an initial INR of $\geq 1.5$ and $<1.8,500 \mathrm{IU}$; INR retesting after $10 \mathrm{~min}$; if the INR remains $>1.8$, administration of another $500 \mathrm{IU}$ and INR retesting until an INR $<1.5$ is achieved.

Additional administration of vitamin $\mathrm{K}$ to avoid VKA-associated INR rebound after reversal treatment [10] and start of low molecular weight heparin (LMWH) for prevention of venous thromboembolism during the first $48 \mathrm{~h}$ after admission were performed upon the decision of the treating physician.

TE and Allergic Event

All TEs as well as allergic and anaphylactic reactions that occurred during treatment in our hospital were identified. In order to diagnose acute myocardial infarction (MI), clinical symptoms,

Cerebrovasc Dis 2016;42:446-454 
electrocardiographic changes, troponin T elevations $(>50 \mathrm{pg} / \mathrm{ml})$ and results of cardiac catheterization were taken into consideration [25]. Deep vein thrombosis was diagnosed by typical clinical signs and/or imaging of the venous system. To diagnose pulmonary embolism (PE), clinical symptoms, vital parameters, ECG changes, blood gas analyses and imaging results were taken into consideration [26]. Ischemic strokes were diagnosed by clinical symptoms and the results of brain imaging [27].

Allergic and anaphylactic reactions were diagnosed in case of new skin exanthemas, rush, pruritus, oro-lingual edema or sudden and otherwise unexplained abnormalities of the cardiorespiratory system [28].

All events were reviewed by 3 reviewers (M.L., O.J.M. and T.R.) following the World Health Organization Collaborating Centre for International Drug Monitoring (Uppsala Monitoring Center) causality assessment system [29]. All events were subsequently categorized in consensus by the reviewers as being 'related', 'probably related', 'possibly related', 'unlikely related' or 'not related' to treatment with PCC.

\section{ICH Enlargement and Clinical Outcome}

ICH was classified according to its location into lobar, deep and infratentorial [30]. To quantify intraventricular hemorrhage, the modified Graeb score was applied [31]. Follow-up brain imaging (CT or MRI) to assess hematoma enlargement was conducted 20-36 h after the initial diagnosis or earlier in case of clinical deterioration. As previously described, planimetric volumetry was performed by the $\mathrm{ABC} / 2$ or, in case of irregularly shaped hematomas, by the $\mathrm{ABC} / 3$ formula $[32,33]$. Substantial hematoma growth was defined as hematoma enlargement of $\geq 33.3 \%$ or $6 \mathrm{ml}$ [34] between initial and follow-up brain imaging. The modified Rankin Scale (mRS) was used to report the functional status before ICH premorbid $\mathrm{mRS}$ (pmRS) and at discharge. Functional independence post ICH was defined in accordance with previous reports [19] as mRS values of $0-3$.

The independent Ethics Committee of the medical faculty of the Heidelberg University approved the study, and the manuscript was developed according to the STROBE guidelines for reporting observational studies [35].

\section{Statistical Analysis}

Most descriptive data are presented in relative frequencies, ordinal and continuous data as medians and interquartile ranges (IQRs). To test for normal distribution, the Kolmogorov-Smirnov test was applied. Depending on the scale level of variables, we used the Mann-Whitney $U$ test for continuous, but not normally distributed variables and the chi-square test for categorical variables to explore differences between groups with regard to the presence of TEs and ICH enlargement. To test associations between INR values and ICH enlargement, Spearman correlations were applied. The time between symptom onset and diagnosis of ICH was categorized into the following intervals: $<2,2-4,4-6,7-12,13-24$ and $>24 \mathrm{~h}$. Based on a previous approach [36], ICH volume at admission was categorized into 6 groups $(<20$ and $\geq 20 \mathrm{ml},<30$ and $\geq 30 \mathrm{ml},<40$ and $\geq 40 \mathrm{ml},<50$ and $\geq 50 \mathrm{ml},<60$ and $\geq 60 \mathrm{ml},<70$ and $\geq 70 \mathrm{ml}$ ). To investigate associations of clinical characteristics and therapeutic variables on TEs, Kaplan-Meier and log rank analyses were used. To compare TE-distributions of different subgroups (e.g., dependent on PCC dosage, stroke severity), we used the log rank test and Kaplan-Meier plots to visualize the estimated sur-
Table 1. Baseline and treatment characteristics of included patients $(\mathrm{n}=205)$

\begin{tabular}{lc}
\hline Clinical characteristics and risk factors & \\
Age, years, median (IQR) & $75.0(69-80)$ \\
Male sex, n (\%) & $133(64.6)$ \\
NIHSS at admission, median (IQR) & $13(6-22)$ \\
pmRS, median (IQR) & $1(0-2)$ \\
Arterial hypertension, n (\%) & $189(91.7)$ \\
Hypercholesterolemia, n (\%) & $62(30.1)$ \\
Statin use, $\mathrm{n}(\%)$ & $52(25.2)$ \\
Diabetes, $\mathrm{n}(\%)$ & $61(29.6)$ \\
History of ICH, $\mathrm{n}(\%)$ & $13(6.3)$ \\
History of TIA/ischemic stroke, $\mathrm{n}(\%)$ & $37(18.0)$ \\
VKA indications, $\mathrm{n}(\%)$ & \\
Atrial fibrillation & $142(69.3)$ \\
Mechanical heart valve & $19(9.3)$ \\
Deep vein thrombosis & $19(9.3)$ \\
PE & $11(5.4)$ \\
Cardiomyopathy & $4(2.0)$ \\
Others/unknown & $8(3.9)$ \\
Symptom onset to diagnosis of ICH, h, $\mathrm{n}(\%)$ & \\
$\leq 2$ & $56(27.3)$ \\
$>2-4$ & $22(10.7)$ \\
$>4-6$ & $39(19.0)$ \\
$>6-12$ & $30(14.6)$ \\
$>12-24$ & $21(10.2)$ \\
$>24$ & $37(18.0)$ \\
PCC dose, IU, n (\%) & \\
$\leq 1,000$ & $61(29.8)$ \\
$>1,000-2,000$ & $82(40.0)$ \\
$>3,000-3,000$ & $40(19.5)$ \\
$>4,000$ & $17(8.3)$ \\
& $5(2.4)$ \\
& \\
&
\end{tabular}

TIA $=$ Transient ischemic attack.

vival curves. To distinguish between severe and light to moderate pre-stroke disability and stroke severity, pmRS and NIHSS values were dichotomized (pmRS: 0-2 and 3-5; NIHSS: 0-10 and 11-42) [37]. PCC dosages were included in Kaplan-Meier plots and log rank tests to test for dose-dependent incidences of TEs by using the following groups: $\leq 1,000$ vs. $>1,000 \mathrm{IU}, \leq 2,000$ vs. $>2,000 \mathrm{IU}$, $\leq 3,000$ vs. $>3,000$ IU and $\leq 4,000$ vs. $>4,000$ IU. A p value of $\leq 0.05$ was considered statistically significant. Data analysis was performed using the Statistical Package for Social Sciences (SPSS) 22.0 for Windows (IBM, Armonk, USA).

\section{Results}

\section{Patient and ICH Characteristics}

Overall, we included 205 patients (c.f. online suppl. fig. 1). Basic demographic variables, cardiovascular risk factors and indications for oral anticoagulation are summarized in table 1 . The median age was 75 years (IQR 69- 
Fig. 1. TE and allergic event during the hospital stay and results of causal relationship to PCC treatment.

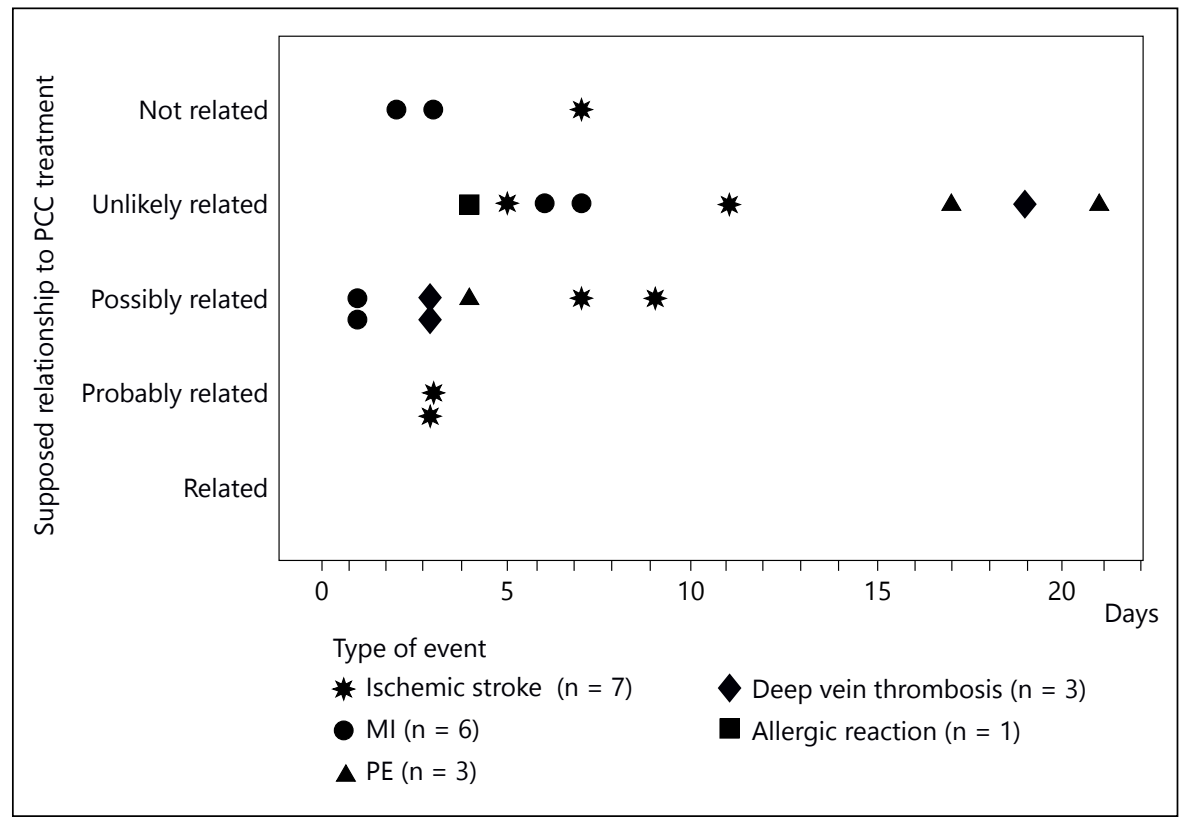

80 ), $64.6 \%$ of patients were male and the median NIHSS at admission was 13 (IQR 6-22). The most common reason for oral anticoagulation was atrial fibrillation (69.3\%), followed by deep vein thrombosis (9.3\%) and mechanical heart valves (9.3\%; table 1$)$. Patients were hospitalized at our center for a median of 6 days (IQR 3-11).

Most hematomas were localized in deep brain structures $(\mathrm{n}=99 ; 48.3 \%)$. Lobar bleeds were observed in 72 patients (35.1\%) and 28 (13.7\%) suffered infratentorial hemorrhages. Pure intraventricular hemorrhages were diagnosed in 6 patients $(2.9 \%)$.

\section{INR Reversal}

At admission, the median INR was 2.8 (IQR 2.2-3.8). A median dose of 1,500 IU PCC (IQR 1,000-2,500) was administered. One hundred and thirty-nine minutes after ICH diagnosis (median; IQR 89-241), the INR was reversed (INR $<1.5)$ and a median INR of 1.3 was observed after completion of PCC treatment (IQR 1.2-1.4; p < $0.001)$.

Within $48 \mathrm{~h}$ after admission, 172 patients (83.9\%) received LMWH for prevention of venous thromboembolism.

\section{TE and Allergic Event}

In total, 19 TEs $(9.3 \%)$ and 1 allergic event $(0.5 \%)$ were identified among the 205 patients (c.f. fig. 1). Ischemic strokes represented the most common type of TEs ( 7 of 19; $36.8 \%$ ), followed by MI ( 6 of 19,31.6\%), PE ( 3 of 19, 15.8\%) and deep vein thrombosis ( 3 of $19,15.8 \%$ ). All ischemic strokes and MIs were observed in patients with AF, and 2 of 3 cases of PEs (66.7\%) occurred in patients who were treated with VKA due to former deep vein thrombosis.

Importantly, none of the events was considered 'related' to treatment with PCC, but 2 of 19 TEs (10.5\%) were categorized 'probably related' to the preceding PCC treatment ( 2 ischemic strokes), and 7 of 19 events (36.8\%) were judged 'possibly related' to treatment with PCC (2 ischemic strokes, 2 MIs, 2 PEs and 1 deep vein thrombosis). All other events were rated as either 'unlikely related' (7 of $19 ; 36.8 \%$ ) or 'not related' ( 3 of $19 ; 15.8 \%$ ) to PCC treatment (fig. 1).

The observed allergic reaction was assessed 'unlikely related' to treatment with PCC; it followed cerebral angiography with iodine-containing contrast medium 4 days after PCC infusion.

\section{Factors Associated with Any TE}

Associations between demographic factors, clinical parameters and treatment-related factors with TEs that were observed are summarized in table 2. Log rank analyses revealed that factors associated with TEs $(\mathrm{n}=19)$ were PCC dosages between $>2,000$ and 3,000 IU ( $p=0.031)$, severe strokes at admission (NIHSS scores $>10 ; \mathrm{p}=0.050$ ) and a pmRS of 3-5 ( $\mathrm{p}=0.016$; table 2). Kaplan-Meier plots for PCC dosages and dichotomized NIHSS values are given in figure 2. Because the assumption of proportional hazards was not fulfilled, Cox regression was not performed. 
Table 2. Association of patients' and treatment characteristics with TEs $(n=19)$ in log rank analysis

\begin{tabular}{|c|c|}
\hline Characteristic & $\mathrm{p}$ value \\
\hline \multicolumn{2}{|l|}{ Demographic data } \\
\hline Age $(\leq 75,>75$ years $)$ & 0.678 \\
\hline Sex (female, male) & 0.120 \\
\hline pmRS $(0-2,3-5)$ & 0.036 \\
\hline \multicolumn{2}{|l|}{ Cardiovascular risk factors } \\
\hline Arterial hypertension (present/absent) & 0.479 \\
\hline Diabetes (present/absent) & 0.520 \\
\hline Hypercholesterolemia (present/absent) & 0.057 \\
\hline \multicolumn{2}{|l|}{ Clinical parameters } \\
\hline NIHSS $(\leq 10,>10)$ & 0.050 \\
\hline Hemorrhage volume $(<20, \geq 20 \mathrm{ml})$ & 0.183 \\
\hline Hemorrhage volume $(<30, \geq 30 \mathrm{ml})$ & 0.312 \\
\hline Hemorrhage volume $(<40, \geq 40 \mathrm{ml})$ & 0.034 \\
\hline Hemorrhage volume $(<50, \geq 50 \mathrm{ml})$ & 0.013 \\
\hline Hemorrhage volume $(<60, \geq 60 \mathrm{ml})$ & 0.109 \\
\hline Hemorrhage volume $(<70, \geq 70 \mathrm{ml})$ & 0.036 \\
\hline Ventricular hemorrhage (present/absent) & 0.103 \\
\hline ICH enlargement (present/absent) & 0.406 \\
\hline Neurosurgical intervention (present/absent) & 0.103 \\
\hline LMWH within $48 \mathrm{~h}$ (present/absent) & 0.922 \\
\hline \multicolumn{2}{|l|}{ Hemostatic treatment } \\
\hline PCC dose $(\leq 1,000,>1,000$ IU $)$ & 0.325 \\
\hline PCC dose $(\leq 2,000,>2,000$ IU $)$ & 0.031 \\
\hline PCC dose $(\leq 3,000,>3,000$ IU $)$ & 0.378 \\
\hline PCC dose $(\leq 4,000,>4,000$ IU $)$ & 0.451 \\
\hline \multicolumn{2}{|l|}{ Functional outcome } \\
\hline $\operatorname{mRS}(0-3,4-6)$ & 0.169 \\
\hline
\end{tabular}

$\mathrm{p}$ values $\leq 0.05$ are shown in bold.

Clinical Outcome and Association with TEs

In-hospital mortality was $27.8 \%(\mathrm{n}=57)$, and $22.0 \%$ $(\mathrm{n}=45 / 205)$ of patients were functionally independent at discharge (mRS 0-3). Expectedly, mortality was higher in patients with hematoma growth $(46.9 \%)$ compared to those without $(13.4 \% ; \mathrm{p}<0.001)$. Mortality rates did not differ between patients with and without TEs (40 vs. $26.8 \% ; p=0.190)$. Moreover, no difference with regard to the rate of functional independency was observed between patients with and without TEs (15.8 and $22.4 \%$ respectively; $\mathrm{p}=0.530)$.

\section{Discussion}

The major findings of this study are that (1) TEs after PCC treatment were observed in $9.3 \%$ of patients but none were classified as 'related' to the treatment with PCC. (2) None of the TEs were classified as 'related' but
TEs were considered 'possibly' or 'probably related' to treatment with PCC in $4.4 \%$ of patients. (3) In patients with PCC, dosages between $>2,000$ up to 3,000 IU TEs compared to lower dosages were observed. (4) Worse premorbid status and higher stroke severity were associated with TEs.

Faster restoration of coagulation and lower infusion volumes represent clear advantages of PCC compared to FFP in anticoagulation reversal in VKA-ICH patients $[10,11,14,16,17,19,21]$. Hence, PCC are widely used in this indication $[22,38]$. However, despite the fact that PCC is frequently used in clinical routine, data on PCCrelated thromboembolic complications in patients with VKA-ICH are still limited [19, 39].

In anticoagulation reversal with PCC not being limited to VKA-ICH patients, thromboembolic complications associated to PCC administration have been reported in $1.8 \%$ in a meta-analysis and in $0.0-7.3 \%[23,39-43]$ among observational cohort studies and randomizedcontrolled trials that included patients with VKA-related bleedings or prior to urgent surgical procedures. Evaluating specifically VKA-ICH patients, a retrospective study with 30 VKA-ICH patients treated with PCC reported a TE rate of $10 \%$ [40]. In the Intracranial Hemorrhage Related to VKA trial [19], 7.4\% of patients within the PCC group ( $\mathrm{n}=27)$ suffered TEs during the first 3 days after treatment, and in $29.2 \%$ of patients, TEs were observed during the observational period of 90 days [19]. On the other hand, in ICH patients who did not have anticoagulation, venous thromboembolism has been reported in 1.9-19.8\% [44-47].

We observed TEs in $9.3 \%$ of patients during the acute hospital stay. All the more, no event was classified 'related' to treatment with PCC, suggesting that the use of PCC for VKA reversal in ICH is sufficiently safe with respect to TEs. Explanations for the higher rate of TEs in VKA-ICH $[19,40]$ compared to inhomogeneous populations that received PCC due to different indications remain speculative. ICH patients are often multimorbid [47] and frequently immobilized [48] during the hospital stay, which comprises a high risk for thromboembolism. Moreover, uniform procedures to report TEs do not exist and causal assessment of TEs related to treatment with PCC is usually challenging. Patients with an indication for anticoagulation are already at an increased risk for systemic thromboembolisms and other comorbidities impede a clear attribution of TEs to PCC, for instance in case of MIs after PCC treatment in patients with coronary heart disease, and it remains unknown until when TEs caused by PCC treatment itself may occur. Moreover, the 


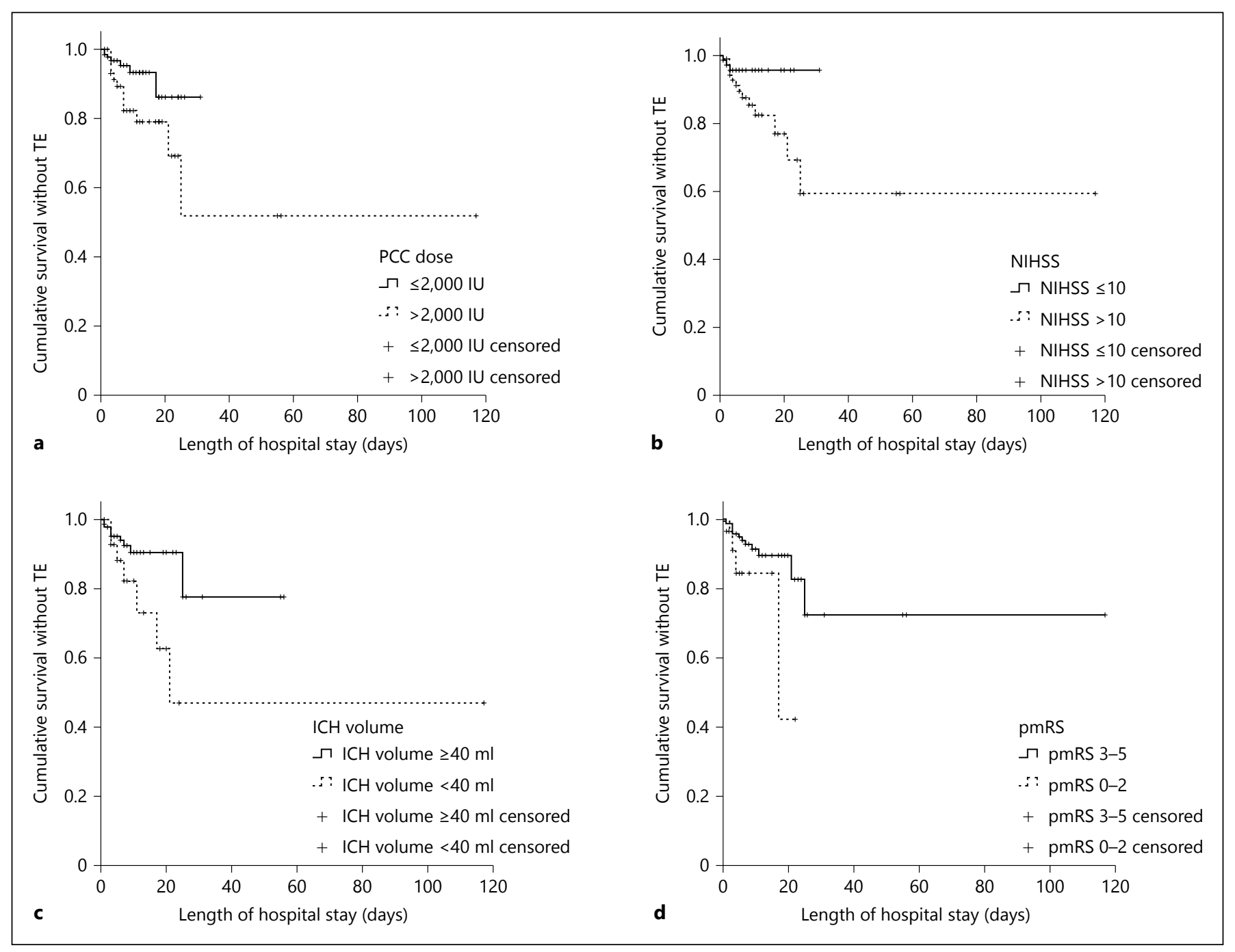

Fig. 2. Plots of the Kaplan-Meier estimator. a Comparing the development of TEs in patients with PCC doses $>3,000$ vs. $\leq 3,000$ IU; $\log$ rank test $\mathrm{p}=0.031$. $\mathbf{b}$ Comparing the development of TEs in patients with NIHSS scores $>10$ vs. $\leq 10 ; p=0.050$. c Comparing

the development of TEs in patients with an ICH volume $\geq 40$ vs. $<40 \mathrm{ml} ; \mathrm{p}=0.034$. $\mathrm{d}$ Comparing the development of TEs in patients with pmRS scores $>2$ vs. $0-2$ on development of TEs; $p=0.036$.

assessment of TEs and their causal relation to PCC therapy differed among studies [15-17, 21, 38, 41, 42] and observation times to evaluate TEs after PCC administration varied considerably (2-90 days) $[16,17,19,21,38$, $39,43,44]$. Hence, it can be assumed, that these factors contribute to considerable differences of reported TEs after PCC treatment.

According to our results, PCC doses between $>2,000$ and 3,000 IU were associated with TEs but a clear relationship between higher PCC dosing and development of TEs was not observed, as in the groups with even higher PCC doses, TEs were not detected more frequently. Reasons for this observation may be the small absolute num-

ber of TEs and the comparatively small number of patients who received particularly very high amounts of PCC (>3,000 IU PCC: 22 vs. 183 patients receiving $<3,000$ IU PCC). Nonetheless, our results suggest that higher PCC doses might be a risk for the development of TEs. Individual titration of PCC [49] to avoid exposure to unnecessarily high doses using point-of-care devices at the bedside is a potential option.

Our findings suggest that $\mathrm{ICH}$ patients with higher disease severity (i.e., NIHSS values $>10$ and hemorrhage volume $\geq 40 \mathrm{ml}$ ) and a restricted premorbid functional status (pmRS $>2$ ), indicating multimorbidity, more often suffered TEs after treatment with PCC. 
Hence, an approach of titrating PCC individually may be most beneficial particularly in these critically ill patients. On the other hand, the optimal procedure to prevent thromboembolism in this subgroup of ICH patients prone to develop TEs during the course of the hospital stay after INR reversal remains unknown [47, 50]. When caring for these patients, one should be aware of higher incidences of TEs in more severely affected VKA-ICH patients. Intermittent pneumatic compression of lower limbs or low-dose LMWH or unfractionated heparin, respectively, is currently recommended to prevent TEs [14]. Nevertheless, optimal measures to prevent TEs in this important subgroup of ICH patients remain unknown and should be evaluated in future studies.

The lack of a control group and the small number of TEs are limiting our results, and because adjustment for multiplicity was not performed, our results can only be interpreted descriptively. Late-onset TEs may have been underestimated because of the limited time of observation (median 6 days). Due to the retrospective characteristic, no standardized follow-up was performed. Moreover, body weight was not measured and no standardized ultrasound screening to detect clinical silent deep vein thrombosis was performed. However, we evaluated a large, homogenous group of patients with VKA-associated non-traumatic ICH and categorized all TE and allergic event carefully.

To conclude, reversal treatment in VKA-ICH with PCC appears safe. Though no clear relationship between higher PCC dosing and development of TEs was observed, PCC doses between $>2,000$ and 3,000 IU and higher morbidity at ICH onset was associated with TEs. Hence, individual titration of PCC to avoid exposure to unnecessarily high doses using point-of-care devices should be prospectively explored.

\section{Disclosure Statement}

None of the authors received any financial compensation for their contribution to this study. Dr. M. Laible was supported by a fellowship of the Medical Faculty, University of Heidelberg, Germany. Dr. C. Beynon has received consulting honoraria and speaker honoraria from Boehringer Ingelheim, speaker honoraria from CSL Behring and research support from Roche Diagnostics. Prof. O.J. Müller has received consulting honoraria from Bayer HealthCare and Boehringer Ingelheim, as well as speakers' honoraria from Bayer HealthCare, Boehringer Ingelheim, BMS Pfizer and Daiichi Sankyo. Dr. J. Purrucker has received honoraria and travel grants from Boehringer Ingelheim and Pfizer, outside the submitted work. Prof. T. Steiner has received research grants from Octapharma, and speaker and consulting honoraria from Bayer, Bristol-Myers Squibb/Pfizer, Boehringer Ingelheim and Daiichi Sankyo. Prof. R. Veltkamp has received consulting honoraria, research support, travel grants and speakers' honoraria from Bayer HealthCare, Boehringer Ingelheim, BMS, Pfizer, Daiichi Sankyo, Amgen, Biogen, Roche Diagnostics, St. Jude Medical and Sanofi Aventis. Prof. P.A. Ringleb das received consulting honoraria, speaker's honoraria and travel support from BMS Pfizer, Boehringer Ingelheim, Bayer HealthCare and Daiichi Sankyo. PD Dr. T. Rizos received consulting honoraria, speaker honoraria and travel support from BMS Pfizer, Boehringer Ingelheim, Bayer HealthCare and Daichii Sankyo. All other authors have nothing to declare.

\section{References}

1 Broderick J, Connolly S, Feldmann E, Hanley D, Kase C, Krieger D, Mayberg M, Morgenstern L, Ogilvy CS, Vespa P, Zuccarello M; American Heart Association; American Stroke Association Stroke Council; High Blood Pressure Research Council; Quality of Care and Outcomes in Research Interdisciplinary Working Group: Guidelines for the management of spontaneous intracerebral hemorrhage in adults: 2007 update: a guideline from the American heart association/ American stroke association stroke council, high blood pressure research council, and the quality of care and outcomes in research interdisciplinary working group. Stroke 2007; 38:2001-2023.

2 Palareti G, Leali N, Coccheri S, Poggi M, Manotti C, D'Angelo A, Pengo V, Erba N, Moia M, Ciavarella N, Devoto G, Berrettini M, Musolesi S: Bleeding complications of oral anticoagulant treatment: an inception-cohort, prospective collaborative study (ISCOAT) Italian study on complications of oral anticoagulant therapy. Lancet 1996;348:423-428.

3 Morgenstern LB, Hemphill JC 3rd, Anderson C, Becker K, Broderick JP, Connolly ES Jr, et al; American Heart Association Stroke Council and Council on Cardiovascular Nursing: Guidelines for the management of spontaneous intracerebral hemorrhage: a guideline for healthcare professionals from the American heart association/American stroke association. Stroke 2010;41:2108-2129.

4 Franke CL, de Jonge J, van Swieten JC, Op de Coul AA, van Gijn J: Intracerebral hematomas during anticoagulant treatment. Stroke 1990;21:726-730.

5 Rosand J, Eckman MH, Knudsen KA, Singer DE, Greenberg SM: The effect of warfarin and intensity of anticoagulation on outcome of intracerebral hemorrhage. Arch Intern Med 2004; 164:880-884.
6 Flibotte JJ, Hagan N, O’Donnell J, Greenberg SM, Rosand J: Warfarin, hematoma expansion, and outcome of intracerebral hemorrhage. Neurology 2004;63:1059-1064.

7 Qureshi AI, Mendelow AD, Hanley DF: Intracerebral haemorrhage. Lancet 2009;373: 1632-1644.

8 Sato S, Delcourt C, Zhang S, Arima H, Heeley E, Zheng D, Al-Shahi Salman R, Stapf C, Tzourio C, Robinson T, Lindley RI, Chalmers J, Anderson CS; INTERACT2 Investigators: Determinants and prognostic significance of hematoma sedimentation levels in acute intracerebral hemorrhage. Cerebrovasc Dis 2016;41:80-86

9 Han MH, Kim JM, Yi HJ, Cheong JH, Ko Y, Kim CH, Kim YS: Predictors of supratentorial deep intracerebral hemorrhage volume and their effect on short-term mortality in Asians. Cerebrovasc Dis 2016;42:319331. 
10 Steiner T, Al-Shahi Salman R, Beer R, Christensen $\mathrm{H}$, Cordonnier C, Csiba L, Forsting M, Harnof S, Klijn CJ, Krieger D, Mendelow AD, Molina C, Montaner J, Overgaard K, Petersson J, Roine RO, Schmutzhard E, Schwerdtfeger K, Stapf C, Tatlisumak T, Thomas BM, Toni D, Unterberg A, Wagner M; European Stroke Organisation: European Stroke Organisation. European Stroke Organisation (ESO) guidelines for the management of spontaneous intracerebral hemorrhage. Int J Stroke 2014;9:840-855.

11 Huttner HB, Schellinger PD, Hartmann M, Köhrmann M, Juettler E, Wikner J, Mueller S, Meyding-Lamade U, Strobl R, Mansmann U, Schwab S, Steiner T: Hematoma growth and outcome in treated neurocritical care patients with intracerebral hemorrhage related to oral anticoagulant therapy: comparison of acute treatment strategies using vitamin $\mathrm{K}$, fresh frozen plasma, and prothrombin complex concentrates. Stroke 2006;37:1465-1470.

12 Casaubon LK, Boulanger JM, Blacquiere D, Boucher S, Brown K, Goddard T, Gordon J, Horton $\mathrm{M}$, Lalonde J, LaRivière $\mathrm{C}$, Lavoie $\mathrm{P}$, Leslie P, McNeill J, Menon BK, Moses B, Penn M, Perry J, Snieder E, Tymianski D, Foley N, Smith EE, Gubitz G, Hill MD, Glasser E, Lindsay P; Heart and Stroke Foundation of Canada Canadian Stroke Best Practices Advisory Committee: Canadian stroke best practice recommendations: hyperacute stroke care guidelines, update 2015. Int J Stroke 2015;10: 924-940.

13 Toyoda K, Steiner T, Epple C, Kern R, Nagayama M, Shinohara Y, Hennerici MG: Comparison of the European and Japanese guidelines for the acute management of intracerebral hemorrhage. Cerebrovasc Dis 2013; 35:419-429.

14 Hemphill JC 3rd, Greenberg SM, Anderson CS, Becker K, Bendok BR, Cushman M, Fung GL, Goldstein JN, Macdonald RL, Mitchell PH, Scott PA, Selim MH, Woo D; American Heart Association Stroke Council; Council on Cardiovascular and Stroke Nursing; Council on Clinical Cardiology: Guidelines for the management of spontaneous intracerebral hemorrhage: a guideline for healthcare professionals from the American heart association/American stroke association. Stroke 2015;46:2032-2060.

15 Frontera JA, Lewin JJ 3rd, Rabinstein AA, Aisiku IP, Alexandrov AW, Cook AM, Del Zoppo GJ, Kumar MA, Peerschke EI, Stiefel MF, Teitelbaum JS, Wartenberg KE, Zerfoss CL: Guideline for reversal of antithrombotics in intracranial hemorrhage: a statement for healthcare professionals from the neurocritical care society and society of critical care medicine. Neurocrit Care 2016;24:6-46.

16 Sarode R, Milling TJ Jr, Refaai MA, Mangione A, Schneider A, Durn BL, Goldstein JN: Efficacy and safety of a 4-factor prothrombin complex concentrate in patients on vitamin $\mathrm{K}$ antagonists presenting with major bleeding: a randomized, plasma-con- trolled, phase IIIb study. Circulation 2013; 128:1234-1243.

17 Lankiewicz MW, Hays J, Friedman KD, Tinkoff G, Blatt PM: Urgent reversal of warfarin with prothrombin complex concentrate. J Thromb Haemost 2006;4:967-970.

18 Goldstein JN, Refaai MA, Milling TJ Jr, Lewis B, Goldberg-Alberts R, Hug BA, Sarode R: Four-factor prothrombin complex concentrate versus plasma for rapid vitamin $\mathrm{K}$ antagonist reversal in patients needing urgent surgical or invasive interventions: a phase $3 \mathrm{~b}$, open-label, non-inferiority, randomised trial. Lancet 2015;385:2077-2087.

19 Steiner T, Poli S, Griebe M, Hüsing J, Hajda J, Freiberger A, Bendszus M, Bösel J, Christensen H, Dohmen C, Hennerici M, Kollmer J, Stetefeld H, Wartenberg KE, Weimar C, Hacke W, Veltkamp R: Fresh frozen plasma versus prothrombin complex concentrate in patients with intracranial haemorrhage related to vitamin $\mathrm{K}$ antagonists (INCH): a randomised trial. Lancet Neurol 2016;15:566573.

20 Goldstein JN, Thomas SH, Frontiero V, Joseph A, Engel C, Snider R, Smith EE, Greenberg SM, Rosand J: Timing of fresh frozen plasma administration and rapid correction of coagulopathy in warfarin-related intracerebral hemorrhage. Stroke 2006;37:151-155.

21 Demeyere R, Gillardin S, Arnout J, Strengers PF: Comparison of fresh frozen plasma and prothrombin complex concentrate for the reversal of oral anticoagulants in patients undergoing cardiopulmonary bypass surgery: a randomized study. Vox Sang 2010;99:251-260.

22 Kuramatsu JB, Gerner ST, Schellinger PD, Glahn J, Endres M, Sobesky J, Flechsenhar J, Neugebauer H, Jüttler E, Grau A, Palm F, Röther J, Michels P, Hamann GF, Hüwel J, Hagemann G, Barber B, Terborg C, Trostdorf F, Bäzner H, Roth A, Wöhrle J, Keller M, Schwarz M, Reimann G, Volkmann J, Müllges W, Kraft P, Classen J, Hobohm C, Horn M, Milewski A, Reichmann H, Schneider H, Schimmel E, Fink GR, Dohmen C, Stetefeld H, Witte O, Günther A, Neumann-Haefelin T, Racs AE, Nueckel M, Erbguth F, Kloska SP, Dörfler A, Köhrmann M, Schwab S, Huttner HB: Anticoagulant reversal, blood pressure levels, and anticoagulant resumption in patients with anticoagulation-related intracerebral hemorrhage. JAMA 2015;313:824-836.

23 Dentali F, Marchesi C, Giorgi Pierfranceschi M, Crowther M, Garcia D, Hylek E, Witt DM, Clark NP, Squizzato A, Imberti D, Ageno W: Safety of prothrombin complex concentrates for rapid anticoagulation reversal of vitamin $\mathrm{K}$ antagonists. A meta-analysis. Thromb Haemost 2011;106:429-438.

24 Makris M, van Veen JJ: Three or four factor prothrombin complex concentrate for emergency anticoagulation reversal? Blood Transfus 2011;9:117-119.

25 Task Force for Diagnosis and Treatment of Non-ST-Segment Elevation Acute Coronary Syndromes of European Society of Cardiology,
Bassand JP, Hamm CW, Ardissino D, Boersma E, Budaj A, Fernández-Avilés F, Fox KA, Hasdai D, Ohman EM, Wallentin L, Wijns W: Guidelines for the diagnosis and treatment of non-ST-segment elevation acute coronary syndromes. Eur Heart J 2007;28:1598-1660.

26 Miniati M, Prediletto R, Formichi B, Marini C, Di Ricco G, Tonelli L, Allescia G, Pistolesi M: Accuracy of clinical assessment in the diagnosis of pulmonary embolism. Am J Respir Crit Care Med 1999;159:864-871.

27 Sacco RL, Kasner SE, Broderick JP, Caplan LR, Connors JJ, Culebras A, Elkind MS, George MG, Hamdan AD, Higashida RT, Hoh BL, Janis LS, Kase CS, Kleindorfer DO, Lee JM, Moseley ME, Peterson ED, Turan TN, Valderrama AL, Vinters HV; American Heart Association Stroke Council, Council on Cardiovascular Surgery and Anesthesia; Council on Cardiovascular Radiology and Intervention; Council on Cardiovascular and Stroke Nursing; Council on Epidemiology and Prevention; Council on Peripheral Vascular Disease; Council on Nutrition, Physical Activity and Metabolism: An updated definition of stroke for the 21st century: a statement for healthcare professionals from the American heart association/American stroke association. Stroke 2013;44:2064-2089.

28 Johansson SG, Bieber T, Dahl R, Friedmann PS, Lanier BQ, Lockey RF, Motala C, Ortega Martell JA, Platts-Mills TA, Ring J, Thien F, Van Cauwenberge P, Williams HC: Revised nomenclature for allergy for global use: report of the nomenclature review committee of the world allergy organization, October 2003. J Allergy Clin Immunol 2004;113:832-836.

29 http://who-umc.org/Graphics/24734.pdf (accessed September 28, 2015).

30 Cordonnier C, Leys D, Dumont F, Deramecourt V, Bordet R, Pasquier F, Hénon $\mathrm{H}$ : What are the causes of pre-existing dementia in patients with intracerebral haemorrhages? Brain 2010;133:3281-3289.

31 Morgan TC, Dawson J, Spengler D, Lees KR Aldrich C, Mishra NK, ET AL; Hanley D; CLEAR and VISTA Investigators: The modified Graeb score: an enhanced tool for intraventricular hemorrhage measurement and prediction of functional outcome. Stroke 2013;44:635-641.

32 Kothari RU, Brott T, Broderick JP, Barsan WG, Sauerbeck LR, Zuccarello M, Khoury J: The ABCs of measuring intracerebral hemorrhage volumes. Stroke 1996;27:1304-1305.

33 Huttner HB, Steiner T, Hartmann M, Köhrmann M, Juettler E, Mueller S, Wikner J, Meyding-Lamade U, Schramm P, Schwab S, Schellinger PD: Comparison of $\mathrm{ABC} / 2$ estimation technique to computer-assisted planimetric analysis in warfarin-related intracerebral parenchymal hemorrhage. Stroke 2006; 37:404-408.

34 Brott T, Broderick J, Kothari R, Barsan W, Tomsick T, Sauerbeck L, Spilker J, Duldner J, Khoury J: Early hemorrhage growth in patients with intracerebral hemorrhage. Stroke 1997;28:1-5. 
35 von Elm E, Altman DG, Egger M, Pocock SJ, Gøtzsche PC, Vandenbroucke JP; STROBE Initiative: The strengthening the reporting of observational studies in epidemiology (STROBE) statement: guidelines for reporting observational studies. Lancet 2007;370: 1453-1457.

36 Dowlatshahi D, Smith EE, Flaherty ML, Ali M, Lyden P, Demchuk AM; VISTA Collaborators: Small intracerebral haemorrhages are associated with less haematoma expansion and better outcomes. Int J Stroke 2011;6:201206.

37 González RG, Furie KL, Goldmacher GV, Smith WS, Kamalian S, Payabvash S, Harris GJ, Halpern EF, Koroshetz WJ, Camargo EC, Dillon WP, Lev MH: Good outcome rate of $35 \%$ in IV-tPA-treated patients with computed tomography angiography confirmed severe anterior circulation occlusive stroke. Stroke 2013;44:3109-3113.

38 Parry-Jones AR, Di Napoli M, Goldstein JN, Schreuder FH, Tetri S, Tatlisumak T, Yan B, van Nieuwenhuizen KM, Dequatre-Ponchelle N, Lee-Archer M, Horstmann S, Wilson D, Pomero F, Masotti L, Lerpiniere C, Godoy DA, Cohen AS, Houben R, Al-Shahi Salman R, Pennati P, Fenoglio L, Werring D, Veltkamp R, Wood E, Dewey HM, Cordonnier C, Klijn CJ, Meligeni F, Davis SM, Huhtakangas J, Staals J, Rosand J, Meretoja A: Reversal strategies for vitamin $\mathrm{K}$ antagonists in acute intracerebral hemorrhage. Ann Neurol 2015;78:54-62.

39 Milling TJ Jr, Refaai MA, Goldstein JN, Schneider A, Omert L, Harman A, Lee ML,
Sarode R: Thromboembolic events after vitamin $\mathrm{K}$ antagonist reversal with 4 -factor prothrombin complex concentrate: exploratory analyses of two randomized, plasma-controlled studies. Ann Emerg Med 2016;67:96105.e5.

40 Cabral KP, Fraser GL, Duprey J, Gibbons BA, Hayes T, Florman JE, Seder DB: Prothrombin complex concentrates to reverse warfarin-induced coagulopathy in patients with intracranial bleeding. Clin Neurol Neurosurg 2013; 115:770-774.

41 Riess HB, Meier-Hellmann A, Motsch J, Elias M, Kursten FW, Dempfle CE: Prothrombin complex concentrate (Octaplex) in patients requiring immediate reversal of oral anticoagulation. Thromb Res 2007;121:9-16.

42 Preston FE, Laidlaw ST, Sampson B, Kitchen S: Rapid reversal of oral anticoagulation with warfarin by a prothrombin complex concentrate (Beriplex): efficacy and safety in 42 patients. Br J Haematol 2002;116:619-624.

43 Evans G, Luddington R, Baglin T: Beriplex $\mathrm{P} / \mathrm{N}$ reverses severe warfarin-induced overanticoagulation immediately and completely in patients presenting with major bleeding. $\mathrm{Br}$ J Haematol 2001;115:998-1001.

44 Skaf E, Stein PD, Beemath A, Sanchez J, Bustamante MA, Olson RE. Venous thromboembolism in patients with ischemic and hemorrhagic stroke. Am J Cardiol 2005;12: 1731-1733.

45 Goldstein JN, Fazen LE, Wendell L, Chang Y, Rost NS, Snider R, Schwab K, Chanderraj R, Kabrhel C, Kinnecom C, Fitzmaurice E, Smith EE, Greenberg SM, Rosand J: Risk of throm- boembolism following acute intracerebral hemorrhage. Neurocrit Care 2009;10:28-34.

46 Lv B, Wang YL, Ying HL, Lou JY, Gen S, Zhang $\mathrm{H}$ : The factors about developing deep venous thromboembolism in the acute phase of intracerebral hemorrhage. Chin J Gerontol 2012;32:2266-2268.

47 Gregory PC, Kuhlemeier KV: Prevalence of venous thromboembolism in acute hemorrhagic and thromboembolic stroke. Am J Phys Med Rehabil 2003;82:364-369.

48 Diringer MN, Skolnick BE, Mayer SA, Steiner T, Davis SM, Brun NC, Broderick JP: Risk of thromboembolic events in controlled trials of rFVIIa in spontaneous intracerebral hemorrhage. Stroke 2008;39:850-856.

49 Rizos T, Jenetzky E, Herweh C, Hug A, Hacke W, Steiner T, Veltkamp R: Point-of-care reversal treatment in phenprocoumon-related intracerebral hemorrhage. Ann Neurol 2010; 67:788-793.

50 Kernan WN, Ovbiagele B, Black HR, Bravata DM, Chimowitz MI, Ezekowitz MD, Fang MC, Fisher M, Furie KL, Heck DV, Johnston SC, Kasner SE, Kittner SJ, Mitchell PH, Rich MW, Richardson D, Schwamm LH, Wilson JA; American Heart Association Stroke Council, Council on Cardiovascular and Stroke Nursing, Council on Clinical Cardiology, and Council on Peripheral Vascular Disease: Guidelines for the prevention of stroke in patients with stroke and transient ischemic attack: a guideline for healthcare professionals from the American heart association/ American stroke association. Stroke 2014;45: 2160-2236. 